\title{
IMPROVEMENT OF THE TECHNOLOGICAL TREATMENT SCHEME OF IRON-CONTAINING WASTEWATER FROM ETCHING OPERATIONS
}

\author{
Mykola Yatskov \\ PhD, Senior Research Scientist, Professor \\ Department of Chemistry and Physics \\ Rivne Technical Professional College of NUWEE \\ National University of Water and Environmental Engineering \\ Orlova str., 35, Rivne, Ukraine, 33017 \\ m.v.yatskov@nuwm.edu.ua \\ Natalia Korchyk \\ PhD, Associate Professor ${ }^{l}$ \\ n.m.korchyk@nuwm.edu.ua \\ Oksana Mysina \\ Senior Lecturer \\ o.i.mysina@nuwm.edu.ua \\ Nadia Budenkova \\ PhD, Associate Professor \\ n.m.budenkova@nuwm.edu.ua \\ ${ }^{1}$ Department of Chemistry and Physics \\ National University of Water and Environmental Engineering \\ Soborna str., 11, Rivne, Ukraine, 33028
}

\begin{abstract}
The aim of the research is to improve the technological scheme of treatment of iron-containing wastewater from etching operations by creating combined systems, including reagent wastewater treatment, their mutual neutralization, regeneration of etching solutions, deep post-treatment using a magnetic device. The main volume of wastewater is treated in centralized systems with partial return of water to the production process. Spent solutions from etching operations are subject to regeneration with return to the production process and partial dosing into the main wastewater stream from flushing operations. The consumption of commercial $\mathrm{HCl}$ is reduced by $50 \%$. The use of hydrogen peroxide can increase the effect of extracting iron from etching solutions by $30 \%$ (total purification effect of $70 \%$ ). Given that deep purification from iron-containing impurities is provided using a magnetic device, the possibilities of practical implementation of reverse osmosis to obtain «pure» water in centralized systems, which can be used for preparation of process solutions and in a mixture with technical water - for flushing operations, increase. In experimental and industrial conditions the expenses of reagents, their concentrations, dosing time are established.
\end{abstract}

Keywords: combined schemes, technological schemes, wastewater, etching operations, iron - containing impurities, magnetic device, regeneration of etching solutions.

DOI: $10.21303 / 2504-5695.2021 .001883$

\section{Introduction}

Etching of steel surfaces involves treatment with acid solutions $\left(\mathrm{HCl}, \mathrm{H}_{2} \mathrm{SO}_{4}\right)$ at elevated temperatures, resulting in the formation of liquid iron-containing waste - wastewater (WW): spent etching solutions (SES), which are characterized as highly concentrated solutions, and washing water (WasW), which belong to the category of concentrated solutions [1].

The main problem of the etching area is the processing of SES, for this purpose local cycles of their disposal, utilization, regeneration are created [2]. The most progressive is the creation of combined systems, in which the bulk of wastewater is treated in centralized systems with partial 
return of water to the production process. SES are subject to utilization or regeneration with partial return of chemical reagents to the production process and are partially dosed into the main WW stream from flushing operations. At such wastewater treatment there is a task of decrease in the general concentration of iron less than $1 \mathrm{mg} / 1$. That is why in accordance with the requirements of environmental legislation on nature management there is a need for deep treatment of such wastewater.

WW treatment with an alkaline reagent, including lime milk, which allows to provide the final total concentration of iron in WW up to $3 \mathrm{mg} / 1$ is widespread in practice. To ensure a concentration of iron in purified water less than $1 \mathrm{mg} / \mathrm{l}$ requires additional (deep) water purification.

Since a significant part of iron-containing impurities has magnetically sensitive properties, it is possible to use the magnetic method in order to purify such WW [3]. For deep purification of water systems from iron-containing impurities, the introduction of magnetic devices is promising, in which the main element is a granular filter load, which is magnetized by an external device that generates a magnetic field. This direction has received intensive development, the thorough theoretical and experimental base of process of deposition is developed, a number of effective designs of magnetic filtration devices is created [4].

\section{Analysis of literature data and formulation of the problem of magnetic purification of water systems}

Innovative technologies and equipment for microarc treatment in rotating magnetic fields [5] for various technological processes: drinking water treatment, treatment of various types of wastewater, sludge elimination, oxidation of phenols, alcohols in WW, neutralization and utilization of water after washing tankers and tanks with oil products, etc are known. The versatility of the proposed technologies is determined by the complexity of the combined system, which provides the following effects: mechanical (shocks of working fluids, intensive dispersion of components and particles and their mixing); destructive, weakening intramolecular and interatomic bonds; hydrodynamic, expressed in significant shear stresses of the fluid of developed turbulence, pressure ripples and flow velocity; hydroacoustic due to smallscale pressure pulsations, intense cavitation of shock waves and secondary nonlinear acoustic effects; microarc and electromagnetic field of eddy current; thermal exposure; hydrolysis reactions. At that the magnetic devices are included in the main system of treatment plants, which also include an ozonation unit, a hydrocyclone, an electrolytic reactor, a settling tank with thin-layer blocks and the like. The application of this technological system is expected to improve the environment, expand opportunities for pollution disposal, for the production of organic fertilizers, building materials, etc. [5].

We believe that more promising is the use of magnetic and magneto-electric wastewater treatment for the removal (separation) of iron-containing impurities as an element of auxiliary systems that provide deep after-treatment of wastewater.

The main element of the magnetic device is a granular load. The load is magnetized by an external electromagnetic field generator.

Effective capture zones are formed between the granules due to high values of the generated magnetic field $\mathrm{H}$, which is much higher than the magnetic field, created by the external magnetizing system, and mostly a high degree of its heterogeneity gradH. The product of these two parameters $\mathrm{H} \cdot \operatorname{gradH}$, the so-called force factor, is essential just near the contact points of the granules. The disadvantages of the known devices are the limited possibilities of creating localized zones of high-gradient electric fields in the working zone of deposition of electrically charged impurities, which leads to low precipitating force on impurity inclusions [4].

The results of research on the technology of magnetic-electric wastewater treatment, conducted earlier, allowed to develop a device that creates a high-gradient magnetic field in the working zone of deposition in combination with a branched filtration surface. This increases the force on electrically charged impurities, especially with a low specific electric charge 
and, as a consequence, provides an increase in the overall efficiency and degree of wastewater treatment [6].

In this technological solution we propose to implement deep purification of wastewater from the etching area from iron-containing impurities using a magnetic device, followed by desalination by reverse osmosis.

\section{Research aim and tasks}

The aim of the research is to improve the technological scheme of treatment of iron-containing wastewater from etching operations by creating combined systems, including a WW treatment reagent, their mutual neutralization, regeneration of etching solutions, deep after-treatment using a magnetic device.

To achieve this goal it was necessary to solve the following tasks:

- to study the technology of wastewater treatment using a magnetic device, in which the main element is a granular filter load, which is magnetized by an external device that generates a magnetic field;

- improvement of the technological scheme of wastewater treatment from surface preparation operations from iron-containing impurities in combined systems, which includes a magnetic device as an auxiliary element.

\section{Research materials and methods}

The research was carried out on the spent technological solutions and washing waters of etching of steels of the enterprise "Hardware Plant" LTD under laboratory and research-industrial conditions.

Acid-base and redox properties of WasW and conditions of their processing for purification, utilization, regeneration were studied by potentiometric titration and chemical precipitation in a batch reactor with intensive stirring of the reactants.

Quantitative analyzes for the content of iron ions were performed in the laboratory by photometric determination with sulfosalicylic acid. Potentiometric titration was performed on a potentiometer EV 74 (in the laboratory) and under industrial research conditions using a portable $\mathrm{pH}$ meter « $\mathrm{pH} 602 »$. The magnetic purification of PV was studied in an experimental setup for magnetic deposition.

\section{Results of research on wastewater treatment technology using a magnetic device}

Improvement of the technological scheme of treatment of iron-containing wastewater from etching operations is achieved by providing deep purification with the use of a magnetic device. The proposed technological solution is the result of the conducted research that meets the conditions for the creation of new equipment (technology).

Studies have been conducted to study the effect of the length (height) of the nozzle layer L, the magnetic field strength $\mathrm{H}$, the filtration rate , using model suspensions of magnetite on an experimental setup including granular filter load, which is magnetized by an external device.

The parameters under consideration can be divided as follows: state parameters particle size of impurities $\delta$, magnetic susceptibility of impurity particles $\chi$, dynamic viscosity of wastewater $\eta$; technological indicators - external magnetic field strength $\mathrm{H}$, filtration rate, , degree of purification $\psi$; design parameters - packing density of the nozzle granules $\gamma$, nozzle granule diameter $\mathrm{d}$, length (height) of the filter nozzle layer.

As a result of the conducted researches it has been established, that the greatest degree of purification of water environments $\psi$ is observed in the following ranges of the basic technological parameters of magnetic deposition: to $5060 \mathrm{kA} / \mathrm{m}$, , to $100150 \mathrm{~m} / \mathrm{h}$, to $0,60,8 \mathrm{~m}$.

The disadvantage of the known magnetic treatment devices, containing granular loading, is the low force on the impurities that are separated (removed) from the wastewater. Researchers (Yatskov M. V., Mysina O. I.) patented the design of the magnetic device, which allows to separate magnetic and non-magnetic impurities of wastewater due to the fact that a high-gradient electric field in combination with a branched magnetic surface is generated in the working area 
of the device. This increases the force on the impurities of wastewater to be separated (especially with a low specific electric charge), and as a result increases the degree of wastewater purification $\psi[6]$.

At the same time, the magnetic device provides for the separation of wastewater impurities into ferromagnetic and non-ferromagnetic fractions by acting on the medium of the magnetized force, generated by the solenoid.

The ferrous wastewater predicted purification degree $\psi$ depending on the intensity of the external magnetic field at a filtration speed of $100 \mathrm{~m} / \mathrm{h}$ and $\mathrm{L}=0.8 \mathrm{~m}$ is 0.60 .7 . Assume that the particle size of the impurities is in the range from 2 to $4 \mu \mathrm{m}$.

As a result of the research in the article a technological solution was proposed, which consists in the fact that the magnetic device is used as an auxiliary element in technological systems of wastewater treatment, namely: wastewater after reagent treatment with coagulant, flocculant, alkaline reagent and after expanded styrofoam filter is fed to a magnetic filter with a granular load. The results of studies of wastewater treatment from the etching area (chloride solution) are given in Table 1.

Table 1

Parameters of wastewater treatment from the etching area (chloride solution)

\begin{tabular}{cccc}
\hline Volume of $\mathbf{4 0} \mathbf{\%} \mathbf{~ N a H}, \mathbf{~} / \mathbf{m}^{\mathbf{3}}$ & $\mathbf{p H}$ & $\begin{array}{c}\text { Iron concentration after } \\
\text { reagent treatment, } \mathbf{g} / \mathbf{l}\end{array}$ & $\begin{array}{c}\text { Iron concentration after an magnetic } \\
\text { device with }=\mathbf{0 . 7}, \mathbf{g} / \mathbf{l}\end{array}$ \\
\hline 0 & 0.7 & 2,5 & - \\
50 & 1 & - & - \\
100 & 1.8 & $0.32 \cdot 10^{-3}$ & $0.096 \cdot 10^{-3}$ \\
200 & 2 & $0.24 \cdot 10^{-3}$ & $0.072 \cdot 10^{-3}$ \\
250 & 2.6 & $0.12 \cdot 10^{-3}$ & $0.036 \cdot 10^{-3}$ \\
450 & 12 & $0.12 \cdot 10^{-3}$ & $0.036 \cdot 10^{-3}$
\end{tabular}

Thus, the use of an electromagnetic device (filter) will provide deep purification of wastewater from iron ions, which is very important for further desalination by reverse osmosis [7] and allows to solve the problem of returning washing water to production processes.

\section{Improvement of the technological scheme of iron-containing wastewater treatment from etching operations}

The basic concept of improving the technological scheme of wastewater treatment from surface preparation operations was formulated in accordance with the environmental requirements of chemical technologies the main principle of which is to reduce the consumption of chemical reagents at the inlet and outlet of the process, including water, which is provided by its deep purification with the return to production and disposal of waste [8].

The surface preparation area includes the following operations: degreasing, two-stage washing (hot and cold), post-degreasing, etching, cold washing after etching.

In order to reduce the consumption of chemical reagents and ensure effective subsequent disposal of toxic waste, we recommend the inclusion of additional process equipment for local cycles of purification of process solutions (Fig. 1).

Spent process solutions from etching operations are fed to local regeneration cycles with a volume of $50 \%$ of the total. The rest of the spent process solution enters the next local cycle (which operates in batch mode). In the local cycle, they are mutually neutralized with spent process solutions from degreasing operations, followed by dosing into the total wastewater stream, which contains flushing wastewater from degreasing and etching operations. The total flow of wastewater together with technological solutions from the operations of etching and degreasing after their mutual neutralization in the local cycle enters the centralized treatment system, which operates semi-continuously.. 


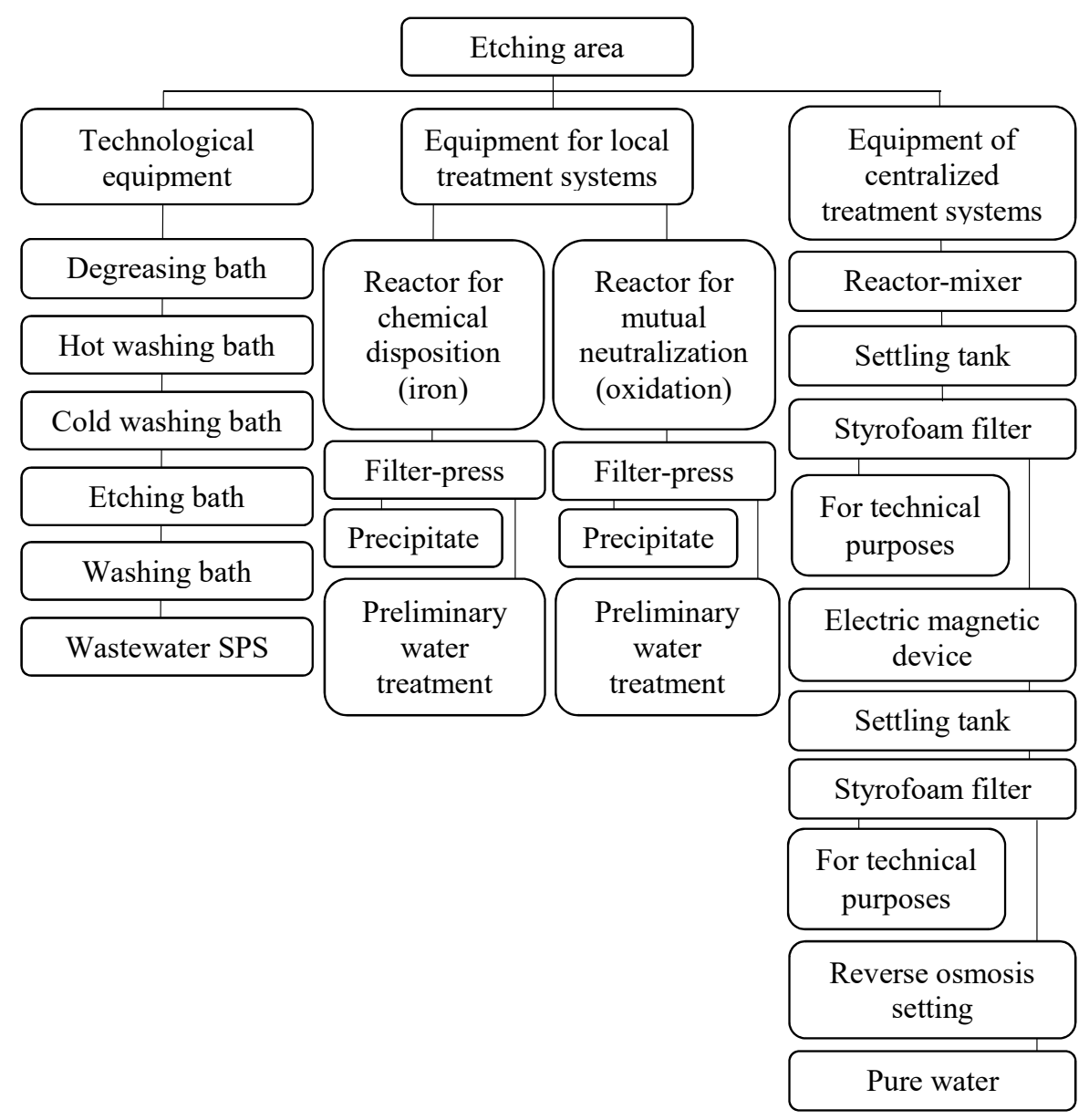

Fig. 1. Block diagram for improving the treatment of iron-containing wastewater from etching operations using a magnetic device

In order to ensure deep wastewater treatment, it is recommended to use additional equipment, namely a magnetic device that provides electromagnetic separation of wastewater impurities (Fig. 1).

Regeneration of solutions from etching operations is carried out by treatment with an alkaline reagent and hydrogen peroxide in an acidic oxide environment in order to precipitate iron ions in the form of hydroxy compounds, followed by separation on a vacuum filter with a chemically resistant fabric. Hydrogen peroxide promotes the formation of hydroxycomplexes of iron (III), which are able to form insoluble compounds in an acidic environment. As an alkaline reagent, it is recommended to use $1020 \% \mathrm{NaOH}$ solution. It should be noted, that the use of lime milk adversely affects the surface of the metal to be etched (see Fig. 2).

As can be seen from the presented data in Fig. 2, application of hydrogen peroxide allows to increase the effect of extracting iron from etching solutions by $30 \%$ (total purification effect $70 \%$ ) under the same conditions at a consumption of an alkaline reagent as 1.5 mol $\mathrm{NaOH}$ per $1 \mathrm{~mol} \mathrm{Fe}^{2+}$. The clarified solution to restore the ability to digest as is enhanced with concentrated $\mathrm{HCl}$ in a ratio of $1: 1$. As a result of the proposed technological solutions, a reduction in the consumption of commercial $\mathrm{HCl}$ by $50 \%$ is provided. The costs of reagents, their concentrations, dosing time, which ensures the extraction of the precipitate of hydroxy compounds of iron of stable composition for its further utilization (processing) are established in experimental and industrial conditions.

Thus, at an acid consumption of $1000 \mathrm{~kg}$ per day, there is a need to discharge the spent solution with a volume of 500 liters, followed by replenishment with new a commercial reagent. Thus, the cost savings of the commercial reagent per year is up to 500,000 conventional units. 


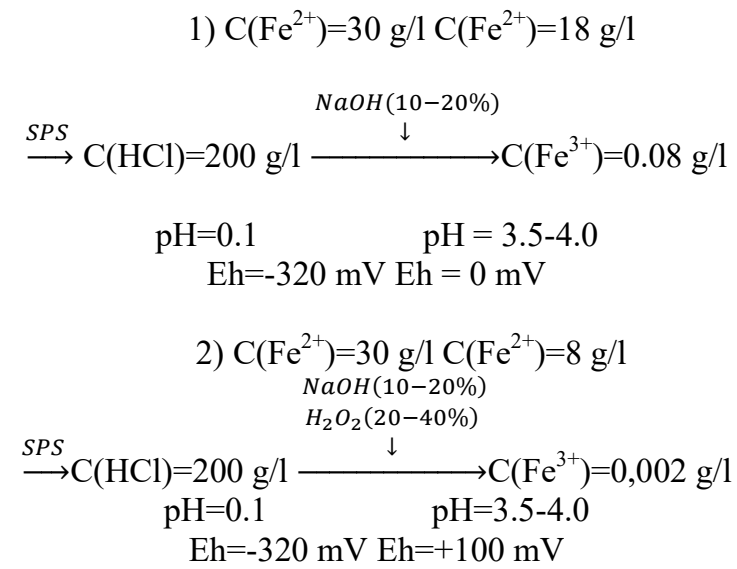

Fig. 2. Scheme of regeneration of spent process solutions (SPS) from etching operations

Approximately one third of the clarified solution $(0.7 \mathrm{~m}$ of clarified filtrate is formed from $1 \mathrm{~m}^{3}$ of spent etching solution, of which $0.5 \mathrm{~m}^{3}$ is returned to the technological process, and $0.2 \mathrm{~m}^{3}$ for mutual neutralization) is sent to the local cycle of mutual neutralization with the technological solution from degreasing operations. The presence of residual concentrations of iron ions and hydrogen peroxide in an alkaline environment provides the conditions for coagulation of surfactants and oils, entering the process solution during degreasing [9]. When using separate streams of spent technological solutions from etching and degreasing operations as chemical reagents, the saving of an alkaline reagent is $80 \%$, the use of an acidic commercial reagent is excluded. Thus, $1,2 \mathrm{~kg} / \mathrm{m}^{3}$ of a sodium hydroxide commercial reagent is consumed per $1 \mathrm{~m}^{3}$ of SPS after their mixing, and without mutual mixing (neutralization) this consumption is $6 \mathrm{~kg} / \mathrm{m}^{3}$. Thus, the savings are about 17,000 conventional units (at the minimum price). The treatment effect increases from 80 to $99 \%$ [9].

For subsequent treatment, wastewater, generated in local cycles, enters the construction of centralized treatment systems.

The main purpose of wastewater treatment ( $80 \%$ of flushing operations and $20 \%$ of local treatment cycles) is to remove iron ions in the form of insoluble hydroxy compounds, which is achieved by dosing an alkaline reagent $(\mathrm{NaOH}$ solution with a concentration of $1 \%)$. At that in order to accelerate the formation phase (insoluble hydroxy compounds), flocculant dosing is recommended. The practical implementation of this process at one of the enterprises of Ukraine allowed to make recommendations for improving the treathemt technology, namely:

- dosing of an alkaline reagent and flocculant can be carried out in one apparatus, such as reactor-mixer - settling tank;

- the subsequent separation of the formed suspension is carried out on the expanded styrofoam filter, which provides additional purification from iron ions in the thickness of the filter load and effective separation of suspended solids;

- for deep purification from iron ions (see Table 2) we recommend using a magnetic device [5]. The use of this device increases the overall threatment efficiency by additional formation of the solid phase of salts, which determine the hardness in the volume of wastewater as it passes through a system of magnets;

- after separation of the additionally formed salt suspension (settling filtration), it is recommended to apply part of the flow to the reverse osmosis unit.

Thus, deep purification from iron-containing impurities with the use of a magnetic device is provided, the possibilities of practical implementation of reverse osmosis to obtain pure water, which can be used for preparation of technological solutions and in a mixture with technical water for washing operations, increase. 
Table 2

Indicators of treatment of iron-containing wastewater from etching operations

\begin{tabular}{ccccc}
\hline Name of inicator & Measuring un. & Before treatment & After treatment & $\begin{array}{c}\text { MPC } \\
\text { Technical water, cate- } \\
\text { gory II [ IV] }\end{array}$ \\
\hline $\mathrm{pH}$ & $\mathrm{un}$ & $5 \div 6$ & $7 \div 8$ & $6 \div 9$ \\
Ferrum, $\mathrm{Fe}^{2+}$, & $\mathrm{Mg} / 1$ & 600 & 0,096 & 0.3 \\
Chlorides, $\mathrm{Cl}^{-}$ & $\mathrm{Mg} / 1$ & 627 & 98 & 100.0 \\
Sulphates, $\mathrm{SO}_{4}^{2-}$ & $\mathrm{Mg} / 1$ & 220 & 69.1 & 150.0 \\
Magnesium, $\mathrm{Mg}^{2+}$ & $\mathrm{Mg} / 1$ & 26.75 & 1.8 & 3.0 \\
Hardness & $\mathrm{Mg}$-equ/l & 10 & 0.8 & 2.0
\end{tabular}

\section{Conclusions}

To improve the technological scheme of wastewater treatment from etching operations from iron-containing impurities in combined systems, it is recommended to use a magnetic device. The main element of the magnetic device is a granular load. The load is magnetized by an external electromagnetic field generator. The use of a magnetic device will provide deep purification of wastewater from iron ions, which is very important for further desalination by reverse osmosis. This solves the problem of returning washing water to production processes, which is the most difficult for chloride etching solutions.

In order to reduce the consumption of chemical reagents and ensure effective subsequent disposal of toxic waste, we recommend the following:

to include additional technological equipment for local cycles of treatment of process solutions and wastewater from flushing operations. This will allow the regeneration of solutions from etching operations (total regeneration volume up to $50 \%$ ) and mutual neutralization of solutions from etching operations and degreasing (total volume up to $50 \%$ ).

Regeneration of solutions from etching operations is carried out by treatment with an alkaline reagent and hydrogen peroxide in an acid-oxide medium in order to precipitate iron ions in the form of hydroxy compounds, followed by separation on a vacuum filter with a chemically resistant fabric.

As a result of the proposed technical solutions, a reduction in the consumption of commercial $\mathrm{HCl}$ by $50 \%$ is provided. In experimental and industrial conditions, the costs of reagents, their concentrations, dosing time, which ensures the extraction of the precipitate of hydroxo compounds of iron of stable composition for its subsequent utilization (processing), are established.

The use of hydrogen peroxide can increase the effect of extracting iron from etching solutions by $30 \%$ (total purification effect $70 \%$ ) under the same conditions at a consumption of an alkaline reagent as $1,5 \mathrm{~mol} \mathrm{NaOH}$ per $1 \mathrm{~mol} \mathrm{Fe}^{2+}$.

We recommend using a magnetic device for deep cleansing from iron ions. The use of this device increases the overall treatment efficiency, including from iron-containing impurities, which expands the implementation of reverse osmosis to obtain «pure» water.

\section{References}

[1] Korchyk, N. M., Bielikova, S. V. (2012). Ochistka i regeneratsiya stochnyh vod gal'vanicheskogo proizvodstva. Ekolohiya plius, 6 (33), 10-13.

[2] Yatskov, M., Korchyk, N., Budenkova, N., Kyrylyuk, S., Prorok, O. (2017). Development of technology for recycling the liquid iron-containing wastes of steel surface etching. Eastern-European Journal of Enterprise Technologies, 2 (6 (86)), 70-77. doi: https://doi.org/10.15587/1729-4061.2017.97256

[3] Sandulyak, A. V., Yatskov, N. V., Shepel', N. I. (1985). Metodika kontrolya magnitnyh svoystv osadkov pri ochistke zhidkostey. Himiya i tekhnologiya vody, 7 (2), 61-63.

[4] Sandulyak, A. V. (1988). Magnitno-fil'tratsionnaya ochistka zhidkostey i gazov. Moscow: Himiya, 136.

[5] Korzhik, V. N., Garnyj, A. I., Shevchenko, V. E., Xaskin, V. Yu., Kostash, S. M. (2017). Application microarc processing in rotating magnetic fields to clean and polluted and waste water. Mezhdunarodniy Nauchniy Institut "Educatio", I (26), 17-27. Available at: https://edu-science.ru/wp-content/uploads/2019/10/17-27-Korzhik-V.N.-Garnyj-A.I.-Shevchenko-V.E.-Xaskin-V. 
Yu_-Kostash-S.M.-Primenenie-mikrodugovoj-obrabotki-vo-vrashhayushhixsya-magnitnyx-polyax-dlya-ochistki-zagryaznennyx-i-stochnyx-vod.pdf

[6] Yatskov, M. V., Mysina, O. I. (1999). Pat. No. 36351 UA. Device for removal of magnetic and non-magnetic inclusions from liquid. No. 99126648; declareted: 07.12.1999; published: 16.04.2001, Bul. No. 3. Available at: https://uapatents.com/3-36351-pristrijj-dlya-ochishhennya-ridini-vid-magnitnikh-ta-nemagnitnikh-vklyuchen.html

[7] Zubchenko, V. L. (Ed.) (1989). Gibkie avtomatizirovannye gal'vanicheskie linii. Moscow: Mashinostroeniya, 672.

[8] Shluger, M. A. (Ed.) (1985). Gal'vanicheskie pokrytiya v mashinostroenii. Vol. 1. Moscow: Mashinostroenie, 240.

[9] Korchyk, N. M., Yatskov, M. V., Bielikova, S. V. (2012). Pat. No. 76053 UA. Process for the purification of waste water of electroplating industry. No. u201206086; declareted: 21.05.2012; published: 25.12.2012, Bul. No. 24. Available at: https://uapatents. com/6-76053-sposib-ochishhennya-stichnikh-vod-galvanichnogo-virobnictva.html

[10] Yatskov, M. V., Mysina, O. I. (2009). Tekhnolohiya mahnitno-elektrychnoho ochyshchennia vodnykh seredovyshch. Visnyk Natsionalnoho universytetu vodnoho hospodarstva ta pryrodokorystuvannia, 3 (47), 343-350.

Received date: 15.04 .2021

Accepted date:18.05.2021

Published date: 31.05.2021
(C) The Author(s) 2021

This is an open access article under the

Creative Commons CC BY license

How to cite: Yatskov, M., Korchyk, N., Mysina, O., Budenkova, N. (2021). Improvement of the technological treatment scheme of iron-containing wastewater from etching operations. EUREKA: Life Sciences, 3, ??-??. doi:https://doi.org/10.21303/ 2504-5695.2021.001883 